\title{
Bazı Kaliks[4, 8]aren Türevlerinin Metal ve Kromat İyon Taşıma Özelliklerinin İncelenmesi
}

\author{
Ömer GÜNGÖR1ㅁำ \\ ${ }^{1}$ Kocaeli Üniversitesi, Hereke Ömer İsmet Uzunyol MYO, Kimya ve Kimyasal İşleme Teknikleri Bölümü, 41800, \\ Kocaeli, Türkiye
}

(Alınıș / Received: 19.12.2018, Kabul / Accepted: 20.08.2019, Online Yayınlanma / Published Online: 30.08.2019)

\section{Anahtar Kelimeler}

Kaliksaren,

Toksik metal,

Sivı-Sıvı ektraksiyon,

Dikromat anyonu
Özet: Bu çalışmada 4-nitrobenziloksi, 4-aminobenziloksi ve 3-aminopropiloksi grupları taşıyan kaliks[4]aren ve kaliks[8]aren bileşikleri literatür metotlara göre sentezlenmiştir. Bu bileşiklerin iyon taşıma özelliklerini görmek için sıvı-sıvı ekstraksiyon çalışmaları metal katyonları $\left(\mathrm{K}^{+}, \mathrm{Na}^{+}, \mathrm{Cs}^{+}, \mathrm{Co}^{2+}, \mathrm{Cd}^{2+}, \mathrm{Ni}^{2+}, \mathrm{Cu}^{2+}, \mathrm{Hg}^{2+}\right.$, ve $\mathrm{Pb}^{2+}$ ) ve kromat iyonu ile yapılmıştır. Ekstraksiyon çalışmaları, amin grubu içeren kaliksarenlerin, nitro grubu taşıyan kaliksarenlere göre metallerle daha yüksek etkileşim yapmalarından dolayı sulu fazdan organik faza taşımasının daha fazla olduğunu göstermiştir. Ayrıca 1 ve 3 bileșiklerin $\mathrm{Na}_{2} \mathrm{Cr}_{2} \mathrm{O}_{7}{ }^{\prime} \mathrm{i}$ düşük pH'larda büyük oranda sulu fazdan organik faza taşıdığı gözlenmiştir.

\section{Investigation of Metal Cation and Dichromate Anios Extraction Properties of Some Calix [4, 8]aren Derivatives}

\section{Keywords}

Calixarene,

Toxic metal,

Liquid-liquid extraction,

Dichromate anions

\begin{abstract}
This work has been synthesized according to literature methods for compounds of calix[4]arene and calix[8]arene bearing 4-nitrobenzyloxy, 4aminobenzyloxy and 3-aminopropyloxy groups. To view the ion transport properties of these compounds liquid-liquid extraction studies were performed with metal cations $\left(\mathrm{K}^{+}, \mathrm{Na}^{+}, \mathrm{Cs}^{+}, \mathrm{Co}^{2+}, \mathrm{Cd}^{2+}, \mathrm{Ni}^{2+}, \mathrm{Cu}^{2+}, \mathrm{Hg}^{2+}, \mathrm{ve} \mathrm{Pb}^{2+}\right)$ and chromate ions. Extraction studies have shown that the amine group-containing calixarenes are large amounts in organic phase transport from the aqueous phase due to higher interaction with the metals than the nitro group-bearing calixarenes. In addition, it was observed that the $\mathbf{1}$ and $\mathbf{3}$ compounds carried $\mathrm{Na}_{2} \mathrm{Cr}_{2} \mathrm{O}_{7}$ to a large extent from the aqueous phase to the organic phase at low $\mathrm{pH}$.
\end{abstract}

\section{Giriş}

Toksik metaller en zararlı çevre kirleticileri arasında yer almaktadırlar. Bu metaller genellikle doğal kaynaklar ve endüstriyel üretim nedeniyle çevrede mevcuttur. Ağır metaller, enzimlerle etkileșen, proteinlerdeki SH grupları ile kuvvetli bağ yapma eğilime sahip ve toksik birtakım üyeleri olan metaller olarak tanımlanır. Bunlardan bazıları ana grup elementleri (Baryum, Talyum, Kurşun) iken bazıları geçiş metalleri ve post-geçiş metalleridir (Kadmiyum, Civa, Bakır, Çinko, Krom). Ağır metallerin inorganik bileşikleri, proteinler ve diğer biyolojik dokularla kuvvetli bağ oluşturmaktadırlar. Bu sebepten dolayı, biyobirikimde artma ve salgllamada da azalma meydana gelmektedir. Bu elementlere maruz kalmak, insanlar üzerinde ciddi etkilere neden olmaktadır. Bu yüksek toksik metallerin, beyin hasarı [1], nefropati [2], halsizlik [3], aşırı duyarlılık [4], huzursuzluk [5] gibi sağlık sorunlarına neden olduğu bilinmektedir. Dokular metallere bağlanmada önemli bir seçicilik göstermektedir. Örneğin Kurşun, kemik dokusunda birikme yaparken Kadmiyum ve Civa böbreklerde birikme yaparlar. Metal iyonlarına bağlanmada en uygun elektron donör grupları, amin ve karboksil gruplarıdır [6]. Son yıllarda endüstriyel ülkelerde zehirli atık bölgelerinin artmasıyla toprak ve sulardaki ağır metal kirliliği de gittikçe artmaktadır. Katı atıklar ise, madencilikte ticari olarak önemli maden cevheri proseslerinden meydana gelmektedir. Uygunsuz olarak yerleştirilen mineral atık yığınları, şiddetli rüzgârlar ve su erozyonu zehirli maddelerin doğaya ve yaşam alanlarına geçmesine sebep olmaktadır. Bu metaller toprak matriksine bir kez bırakıldığında kuvvetli bir şekilde tutunurlar. Böylece insan sağlı̆̆ı ve çevre kirliliğine etkisi artmaktadır. 
Oksianyonlar çevre için tehlikeli kimyasallardır [7]. Bunlardan kromat, dikromat, fosfat, arsenat ve nitrit en yaygın olanlarıdır. Günümüzde krom ve bileşikleri kaplama, deri tabaklama, boya, çimento ve fotoğraf endüstrilerinde büyük miktarlarda kullanılmakta ve toksik kirleticiler üretmektedirler [8]. Krom'un özellikle üç ve altı değerlikli olan bileşikleri çevre için önemlidir. Cr(III) bileşiği memelilerde biyolojik olarak gerekli olan glikoz, lipit ve protein metabolizmaları için önemlidir. Bununla birlikte, krom (VI), hücre zarları boyunca $\mathrm{Cr}_{2} \mathrm{O}_{7}{ }^{2-}$ veya $\mathrm{HCr}_{2} \mathrm{O}_{7^{-}}$olarak yayılabildiği ve biyolojik molekülleri oksitleyebildiği için yüksek oranda toksik özellik göstermektedir [9]. Bu yüzden $\mathrm{Cr}$ (VI) içeren atık suların deşarj edilmeden önce arıtılması önemlidir. Sıvı-sıvı ekstraksiyon yöntemi en yaygın kullanılan arıtma yöntemlerinden biridir.

Kaliksarenler, fenol ve formaldehitin bazik ortamda kondensasyonu ile sentezlenen makrosklik bileşiklerdir. Kaliksarenler konuk (host) moleküllerdir ve konuk-konak (host-guest) kimyasının önemli bir sınıfını teşkil etmektedir. Son yıllarda, oligofenol ailesinden olan kaliksarenler molekül yapısı ve kompleks oluşturma özelliklerinden dolayı supramoleküler kimyanın çok önemli yapı blokları olduğunu kanıtlamıştır. Özellikle, metal iyon sensörleri elde etmek için, kaliks[4]aren yapı bloğu içeren katyon kompleksleştirici ligandlar sentezlenmiştir. Kaliksarenlerin ester, amin ve amid türevleri, birçok metal iyonları ile kompleks oluşturma yeteneğine sahip oldukları bilinmektedir [10]. $\mathrm{Bu}$ çalışmada literatürdeki metotlara göre sentezlenen 4-nitrobenziloksi, 4-aminobenziloksi ve 3-aminopropiloksi fonksiyonel gruplara sahip kaliks[4]aren ve 4-nitrobenziloksi, 4-aminobenziloksi kaliks[8]aren türevlerinin toksik metallere ve kromat anyonuna karşı sıvı-sıvı ektraksiyon özellikleri incelenmiştir.

\section{Materyal ve Metot}

\subsection{Kullanılan kimyasallar}

Sulu fazın pH'ı uygun miktarda $\mathrm{NaOH}$ veya $\mathrm{HCl}(0.1$ M) karıştırılarak ayarlandı. Bu çalışmada kullanılan kaliksaren türevleri literatürdeki metoda göre sentezlenmiştir [11-13]. Diklormetan Merck firmasından hazır temin edildi.

\subsection{Kullanılan cihazlar}

Sulu çözeltiler, Millipore Milli-Q Plus su arıtma sisteminden geçirilmiş deiyonize su ile hazırlandı. $\mathrm{pH}$ ayarlaması pH metre (WTW pH 720) ile yapıldı. UVVis spektrumları Shimadzu $2101 \quad$ UV spektrofotometre ile kaydedildi.

\subsection{Sıvı-sıvı ekstraksiyon}

Sıvı-sıvı ekstraksiyonu Pedersen prosedürüne göre yapılmıştır [14]. Metal iyon ekstraksiyonu için su içerisinde $10 \mathrm{~mL} 1 \times 10^{-5} \mathrm{M}$ metal pikrat çözeltisi ile $\mathrm{CH}_{2} \mathrm{Cl}_{2}$ içinde $10 \mathrm{~mL} 1 \times 10^{-3} \mathrm{M}$ kaliksaren türevi karıştırılarak ağzı kapalı bir erlen içerisine alınır. Kromat ekstraksiyon çalışması için ise, $1 \times 10^{-4} \mathrm{M}$ dikromat çözeltisi, $\mathrm{CH}_{2} \mathrm{Cl}_{2}$ içinde $10 \mathrm{~mL} 1 \times 10^{-3} \mathrm{M}$ kaliksaren türevi ile karıştırılarak ağzı kapalı bir erlen içerisine alındı. Hazırlanan karışımlar mekanik sallayıcıda 3 dakika kuvvetli bir şekilde sallandı. Daha sonra termostatlı su banyosunda oda sıcaklığında 1 saat karıştırıldı. Fazların tam olarak ayrılması için 15 dakika beklendikten sonra metal pikrat ve kromat konsantrasyonu bir UV-Vis spektrometresi (Shimadzu 2101) kullanılarak belirlendi. Ekstraksiyon yüzdesi aşağıdaki denklem kullanılarak hesaplanmiştır,

$$
E \%=\frac{A o-A}{A o} \times 100
$$

burada A ve Ao, sirasiyla ekstraksiyondan önce ve sonra sulu çözeltideki ligandın absorbsiyonudur.

\section{Bulgular}

Kaliks[4]arenlerinin bağlanma yetenekleri, makrosiklik halka boyutuna (cavite), bunların konformasyonuna ve fonksiyonel grupların yapısına bağlıdır. Bu çalışmada, 3-aminopropiloksi (1), 4nitrobenziloksi (2) ve 4-aminobenziloksi (3), grupları taşıyan kaliks[4]aren bileşikleri ve 4-nitrobenziloksi (4), 4-aminobenziloksi (5) grupları taşıyan kaliks[8]aren bileşikleri literatürdeki metotlara göre sentezlenmiştir (Şekil 1 ve 2). Kalis[4,8]aren türevinin atık sulardan ağır metallerin ve dikromat anyonu taşıma özelliğini incelemek için sıvı-sıvı ekstraksiyon deneyleri gerçekleştirilmiştir. Metal iyonlarının ekstraksiyon yüzdesini belirlemek için sülfat, nitrat veya klorür tuzları yerine metal pikrat tuzları tercih edilmiștir. Çünkü metal pikratlar, 270$300 \mathrm{~nm}$ dalga boyunda absorpsiyona bağlı olarak UVVis spektrometresi ile kolayca belirlenebilmektedir. Ayrıca literatürde birçok çalışmada pikrik asit kullanılmıştır. Elde edilen sıvı-sıvı ektraksiyon sonuçları Tablo 1 ve Tablo 2'de verilmiștir.
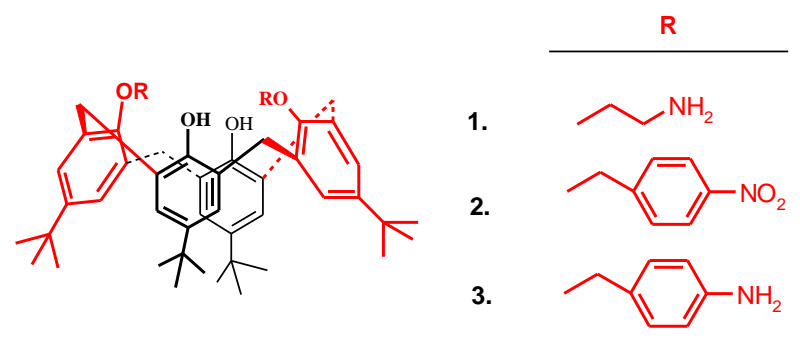

Şekil 1. Bu çalıșmada kullanılan kaliks[4]arenlerin kimyasal yapıları 
Tablo 1. Metal iyonlarının ekstraksiyon değerleri

\begin{tabular}{lccccccccc}
\hline & \multicolumn{10}{c}{ \% Ekstraksiyon } \\
\hline Bileşik & $\mathbf{N a}^{+}$ & $\mathbf{K}^{+}$ & $\mathbf{C s}^{+}$ & $\mathbf{C u}$ & $\mathbf{C o}^{2+}$ & $\mathbf{C d}^{2+}$ & $\mathbf{H g}^{2+}$ & $\mathbf{N i}^{2+}$ & $\mathbf{P b}^{2+}$ \\
\hline $\mathbf{1}$ & 56.1 & 58.2 & 61.9 & 63.5 & 64.2 & 61.6 & 64.6 & 69.2 & 60.2 \\
$\mathbf{2}$ & $<1.0$ & $<1.0$ & $<1.0$ & $<1.0$ & $<1.0$ & $<1.0$ & $<1.0$ & $<1.0$ & $<1.0$ \\
$\mathbf{3}$ & 66.5 & 61.8 & 62.3 & 65.5 & 64.9 & 61.7 & 66.2 & 64.2 & 60.3 \\
$\mathbf{4}$ & $<1.0$ & $<1.0$ & $<1.0$ & $<1.0$ & $<1.0$ & $<1.0$ & $<1.0$ & $<1.0$ & $<1.0$ \\
$\mathbf{5}$ & 12.4 & 11.8 & 8.9 & 13.6 & 14.1 & 13.4 & 17.8 & 11.9 & 14.8 \\
\hline
\end{tabular}

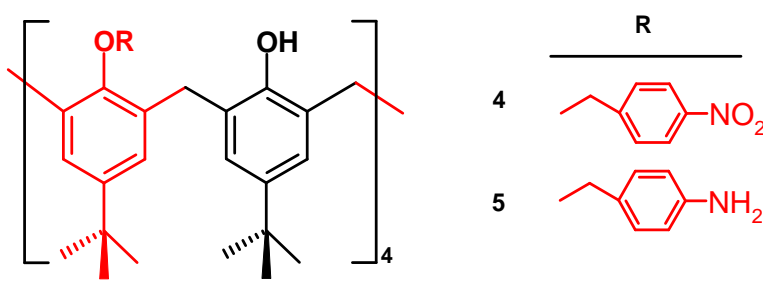

Şekil 2. Bu çalışmada kullanılan kaliks[8]arenlerin kimyasal yapıları

Genel olarak katyonlarla reseptör arasındaki etkileşimler hidrojen bağı, iyon etkileşimi, $\pi-\pi$ etkisi gibi kovalent olmayan etkileşimlere dayanmaktadır. Ektraksiyon çalışmalarında ilk olarak pikrik asit'in ekstraksiyona etkisini incelemek amacıyla kaliksarenin olmadığı ortamda ekstraksiyon çalışması yapılmıştır. Kontrol çalışmasında sulu fazdan organik faza herhangi bir geçişin olmadığı görülmüştür. Bu sonuç iyonların kaliksaren ile yaptıkları kompleks sonucunda taşındığını göstermektedir. p-tert-bütil kaliks[4]aren ve $p$-tert-bütil fenol'ün metallerle kompleks olușturmadıkları bilinmektedir [15]. Bu yüzden kaliksarenler çeşitli fonksiyonel gruplarla sübstitüe edilerek atık sulardan metallerin arıtılması amaçlanmaktadır. Bileşik 2 ve 4 'de bulunan nitro grupları ile iyonlar arasında (metal ve kromat) herhangi bir etkileşim olmadığı için metal ve kromat iyonlarını sulu fazdan organik faza taşımamışlardır. $\mathrm{Bu}$ yüzden nitro grupları literatürdeki metoda göre indirgenerek amin grubuna dönüştürülmüştür.

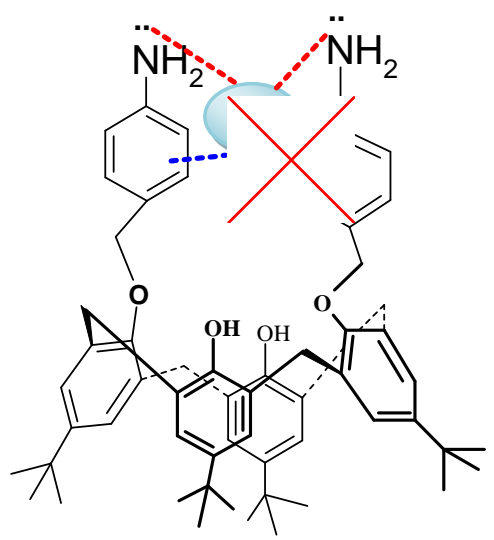

Şekil 3. Bileşik 3 ile metal arasında önerilen kompleks modeli.

Amin grup içeren bileşik $\mathbf{1}$ ve $\mathbf{3}$ ile yapılan ekstraksiyon çalışmalarında bileşiklerin hem alkali metaller hem de geçiș metallerini önemli oranda sulu fazdan organik faza taşıdığı gözlemlenmiștir. $\mathrm{Bu}$ durum literatür ile uyum içinde olup sübstitüe grup ile alkali metallerin arasındaki elektrostatik etkileşim sayesinde olduğu düşünülmektedir [16]. Bileşik 3 ile metaller arasındaki önerilen kompleksleşme modeli şekil 3'te verilmiştir. Bileşik 3'ün Bileşik 1'e göre metal katyonunu sulu fazdan organik faza taşıması biraz daha fazladır. Bu sonuç, Bileşik 3'ün fonksiyonel grubunda bulunan benzen halkası ile metal arasında oluşan $\pi-\pi$ etkileşmesinden kaynaklanabilir. Bileșik 1 ve 3 'ün amin grupları ile metaller arasındaki güçlü etkileşimden dolayı metal katyonlarına karşı seçiciliğ̆i yoktur.

Metal-ligand komplekslerinin yapısal ve geometrik esnekliği, katyon bağlama gruplarını organize etmenin mükemmel bir yoludur. Metallerin kaliksarenlerle kompleks oluşturabilmesi için, kaliksarenin halka boşluğunun metale uygun olması gerekmektedir. Bu çalışma sonucunda kaliks[4]aren türevlerinin (1 ve $\mathbf{3}$ ) halka boşluğunun metaller için uygun olduğu görülmektedir. Ayrıca kaliks[8]arenler'in amin türevinin (5) halka boşluğunun çok büyük olduğu için metal iyonlarını az oranlarda tutulabildiği görülmektedir. Metal iyonları ilk aşamada bileșik $\mathbf{5}$ ile kompleks oluşturmaktadır. Fakat bileşik 5'in boşluğu metale göre çok büyük olduğu için oluşan bu kompleks bileşik 1 ve 3'ün oluşturduğu komplekse göre çok daha zayıf olmaktadır. Dolayısıyla metal, bileşik $\mathbf{5}^{\prime}$ in bu boşluğuna tutunamayarak çıkmaktadır ve kompleks bozulmaktadır. $\mathrm{Bu}$ sonuç literatürle uyumludur [6].

Tablo 2. Dikromat iyonunun ekstraksiyon değerleri

\begin{tabular}{ccccc}
\multirow{2}{*}{ Ligand } & \multicolumn{4}{c}{ \% Ekstraksiyon } \\
& $\mathrm{pH}=1.5$ & $\mathrm{pH}=2.5$ & $\mathrm{pH}=3.5$ & $\mathrm{pH}=4.5$ \\
\hline 1 & 61.8 & 47.5 & 32.3 & 14.9 \\
3 & 65.9 & 48.4 & 34.7 & 16.1 \\
5 & 15.4 & 9.5 & $<1.0$ & $<1.0$ \\
\hline
\end{tabular}

Çalışmanın ikinci aşamasında sentezlenen amin grubu taşıyan kaliksaren türevlerinin $(\mathbf{1}, \mathbf{3}$ ve $\mathbf{5})$ toksik bir oksianyon olan dikromat anyonu taşıma özelliğini incelemek amacıyla sıvı-sıvı ekstraksiyon deneyleri gerçekleştirilmiştir. Kromat ekstraksiyonunda en önemli parametrelerden birinin $\mathrm{pH}$ olduğu bilinmektedir. $\mathrm{Bu}$ yüzden ekstraksiyon çalışmaları farklı pH larda yapılmıştır. Kaliks[8]aren türevi (5) hariç diğer bileşiklerin 
düşük pH larda dikromat anyonunu yüksek oranlarda organik faza taşıdığı görülmüştür. $\mathrm{Bu}$ anyon hidrasyonu ile açlklanabilmektedir. Hofmeister, sıvl-sıvı ekstraksiyonda hidrasyonun önemini açıklamıştır [17]. Düşük pH'lı çözeltide dikromat iyonu protonlanmış $\mathrm{HCr}_{2} \mathrm{O}_{7}$ - şeklinde bulunmaktadır. Mono anyon $\left(\mathrm{HCr}_{2} \mathrm{O}_{7^{-}}\right)$, dianyonik şekli olan $\mathrm{Cr}_{2} \mathrm{O}_{7}{ }^{2-}$ 'den daha az hidrasyon serbest enerjisine sahiptir. Bundan dolayı dikromatın, $\mathrm{HCr}_{2} \mathrm{O}_{7}{ }^{-}$şeklinde sulu fazdan organik faza taşınması daha kolaydır. $\mathrm{HCr}_{2} \mathrm{O}_{7}^{-}$şeklinin $\mathrm{Cr}_{2} \mathrm{O}_{7}^{2-}$ dan daha avantajlı olmasının bir diğer nedeni ise, $\mathrm{HCr}_{2} \mathrm{O}_{7}^{-}$bir sodyum iyonuyla dengeye gelirken $\mathrm{Cr}_{2} \mathrm{O}_{7}{ }^{2-}$ iyonu iki sodyum ile dengeye gelmektedir. Bundan dolayı dikromat anyonu, düşük pH'larda sulu fazdan organik faza daha yüksek oranda taşınmaktadır. Ayrıca kaliks[8]arenlerin halka boşluğu kromat anyonu için çok büyük olduğundan, bileşik 5'nın kromat iyonunu sulu fazdan organik faza düşük oranda taşıyabildiği gözlenmiştir. $\mathrm{Bu}$ sonuçlar, kaliks[4]arenin amin (1 ve $\mathbf{3}$ ) türevlerinin atık sulardan toksik dikromat anyonunun temizlenmesinde kullanılabileceği göstermektedir.

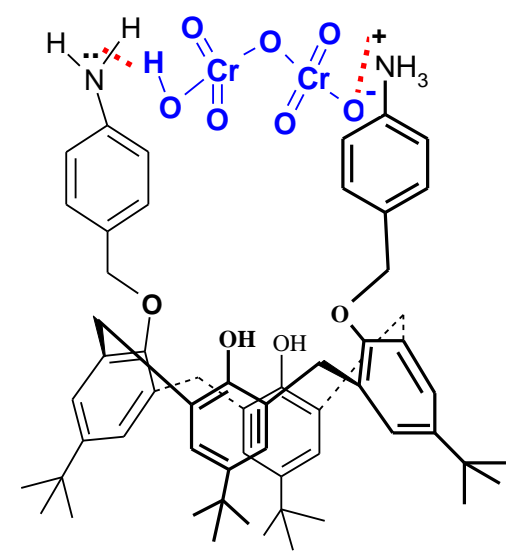

Şekil 4. Bileşik 3 ile dikromat arasında önerilen kompleks modeli. $(\mathrm{pH}=1,5)$

\section{Tartışma ve Sonuç}

$\mathrm{Bu}$ çalışmada, önce literatürdeki metotlara göre kaliks[4]aren ve kaliks[8]arenin 4-nitrobenziloksi türevi sentezlenmiştir. Nitro grubu ile iyonlar (metal ve kromat) arasında etkileşim olmadığı için bu bileşikler atı sulardan iyonların temizlenmesinde etkili olmamıştır. Amin grupları ile metal ve kromat iyonları arasında elektrostatik etkileşim olduğundan dolayı, nitro grupları amin'e indirgenmiştir. Ayrıca $\pi$-iyon etkileşiminin ektraksiyona etkisini incelemek için 3aminopropiloksi kaliks[4]aren(1) türevi literatüredeki metoda göre sentezlenmiştir. Extraksiyon çalışmaları sonucunda amin gruplu kaliks[4]arenelerin çalışılan iyonları sulu fazdan organik faza taşıdığı görülmüştür. Ayrıca elektrostatik etkileşimin yanı sıra $\pi$-iyon etkileşiminden dolayı bileşik 3'ün en yüksek ekstraksiyon yüzdesine sahip olduğu görülmüştür. $\mathrm{Bu}$ çalışma sonucunda amin grubu taşıyan kaliksarenlerin (1, 3 ve $\mathbf{5})$ atık sulardan, çalışılan metaller ve kromat anyonunun temizlenmesinde kullanılabileceği görülmektedir.

\section{Kaynakça}

[1] Antonio, M.T., Corredor, L., Leret, M. L. 2003. Study of the activity of several brain enzymes like markers of the neutrotoxicity induced by perinatal exposure to lead and/or cadmium. Toxicology Letters, 143 (2003), 331-340.

[2] Fels, L.M. 1999. Risk assessment of nephrotoxicity of cadmium. Renal Failure, 21, (1999), 275-281.

[3] Klassen, C.D., Amdur, M.D., Dull, J., 1986. Casarett and Doull's Toxicology, 3rd ed., MacMillan, New Yorki 314s.

[4] Fergusson, J.E., 1990. Heavy Elements: Chemistry Environmental Impact and Health Effects, Pergamon Press, Oxford, 510s.

[5] Kaim, W., Schwederski, B. 1991. Bioinorganic Chemistry: Inorganic Elements in the Chemistry of life, an Introduction and Guide, WileyInterscience, New York, 335s.

[6] Tabakçl, M. 2006. Toksik anyon ve katyonlarin kaliksarenler kullanilarak nanofiltrasyon ve adsorpsiyon teknikleriyle giderilmesi. Selçuk Üniversitesi, Fen Bilimleri Enstitüsü, Doktora Tezi, 26s, Konya.

[7] Tabakci, M., Memon, S., Yilmaz, M., Roundhill, D.M., 2003. Synthesis and extraction studies of a versatile calix [4] arene-based "protonswitchable extractant" for toxic metals and dichromate anions. Journal of inclusion phenomena and macrocyclic chemistry, 45(34), 267-270.

[8] Böhmer, V., Vogt, W., Harris, S.J., Leonard, R.G., Collins, E.M., Deasy, M., McKervey, M.A., Owens, M., 1990. Selective monohydrolysis of a calix [4] arene tetraethyl ester with trifluoroacetic acid and its inhibition by $\mathrm{Na}+$ ion: evidence for hydronium ion complexation. Journal of the Chemical Society, Perkin Transactions 1, (2), 431-432.

[9] Busch, D.H., 1993. The complete coordination chemistry-one practioner's perspective. Chemical reviews, 93(3), 847-860.

[10] Memon, S., Akceylan, E., Sap, B., Tabakci, M., Roundhill, D.M., Yilmaz, M., 2003. Polymer supported calix [4] arene derivatives for the extraction of metals and dichromate anions. Journal of Polymers and the Environment, 11(2), 67-74.

[11] Tabakci, M., Memon, S., Yilmaz, M., Roundhill, D.M., 2004. Synthesis and evaluation of extraction ability of calix [4]-crown-6 cone conformer and its oligomeric analogue. 
Reactive and Functional Polymers, 58(1), 2734.

[12] Tabakci, M., Memon, S., Yilmaz, M., Roundhill, D.M., 2004. Oligomeric calix [4] arene-thiacrown ether for toxic heavy metals. Journal of Polymer Science Part A: Polymer Chemistry, 42(1), 186-193.

[13] Erdemir, S., Deveci, P., Taner, B., Kocyigit, 0. 2012. Synthesis and electrochemical properties of calix[4]arene derivatives containing ferrocene units in the cone and 1,3alternate conformation. Tetrahedron. 68, (2012), 642-646.

[14] Güngör, Ö., Memon, S., Yılmaz, M., Roundhill, M.D. 2005. Synthesis of alkyl nitrile and alkyl benzonitrile derivatives of calix [4] arene and their polymer supported analogues: a comparative study in two-phase extraction systems. Reactive and Functional Polymers. 63, (2005), 1-9.

[15] Pedersen, C.J. 1968. Ionic complexes of macrocyclic polyethres, Federation Proceedings. 27, (1968), 1305-1309.

[16] Roundhill, D.M., 1995. Metal complexes of calixarenes. Kenneth D. K. (Ed.) In Progress in inorganic chemistry, s. 533-592.

[17] Yilmaz, M., Sayin, S., 2016. Calixarenes in organo and biomimetic catalysis. Neri, P., Sessler, J.L., Wang, M.X. (Eds.), In Calixarenes and Beyond s. 719-742.

[18] Kavallieratos, K., Moyer, B.A., 2001. Attenuation of Hofmeister bias in ion-pair extraction by a disulfonamide anion host used in strikingly effective synergistic combination with a calix-crown Cs+ host. Chemical Communications, (17), 1620-1621. 